\title{
A Retrospective Observational Study Comparing ABO Blood Group and Rh Factor Distribution in Patients with Rheumatic Diseases and Healthy Donors in Southern India
}

\author{
Arindam Nandy Roy ${ }^{*}$, Yarram Ashok Kumar, Regina Lata Thadigiri \\ Department of Rheumatology, Yashoda Hospital, Telangana, India \\ Email address: \\ doctor.arindam@yahoo.com (A. N. Roy), yak5686@gmail.com (Y. A. Kumar), regina.thadigiri@gmail.com (R. L. Thadigiri) \\ ${ }^{*}$ Corresponding author
}

To cite this article:

Arindam Nandy Roy, Yarram Ashok Kumar, Regina Lata Thadigiri. A Retrospective Observational Study Comparing ABO Blood Group and Rh Factor Distribution in Patients with Rheumatic Diseases and Healthy Donors in Southern India. American Journal of Internal Medicine. Vol. 9, No. 3, 2021, pp. 107-113. doi: 10.11648/j.ajim.20210903.11

Received: March 31, 2021; Accepted: April 19, 2021; Published: April 29, 2021

\begin{abstract}
Association between $\mathrm{ABO}$ blood group and rheumatic diseases is not well characterized. This study assessed distribution of $\mathrm{ABO}$ blood group and $\mathrm{Rh}$ factor in patients with rheumatic diseases and healthy blood donors. We retrospectively evaluated data of patients with rheumatic diseases who attended the hospital from September 2015 to January 2020, and the documented evidence of blood group of healthy blood donors. Data from 5000 healthy donors and 3165 patients with rheumatic disease were assessed. Overall, blood type $\mathrm{O}$ was the most prevalent (42.94\% and $43.14 \%$ ) followed by B (33.21\% and $30.08 \%)$, A (17.66\% and $21.48 \%)$ and $\mathrm{AB}$ $(6.19 \%$ and $5.30 \%)$ in patients with rheumatic disease and healthy donors, respectively. This distribution was statistically different between the groups, with blood group A being more common in healthy donors than in patients with rheumatic disease $(P<0.0001)$. Distribution of ABO groups among rheumatic disease types was similar $(P=0.2921)$. More individuals had Rhesus $(\mathrm{Rh})(+)$ factor (93.97\%) than $\mathrm{Rh}(-)(6.03 \%)$, however, its distribution was comparable across healthy donors and patients with rheumatic disease $(P=0.1145)$. Patients with blood group A had significantly lower risk of developing rheumatic diseases compared to blood group $\mathrm{O}$ (OR [95\% CI]: 0.94 [0.780, 1.134]; $P<0.0318)$. Similarly, patients bearing blood type $\mathrm{A}+(0.98[0.62,1.54] ; P=0.0037)$ and $\mathrm{O}+(1.08$ $[0.694,1.68] ; P=0.0215)$ were at a lower risk for developing rheumatic diseases compared to those with O- blood group. The most common blood type was $\mathrm{O}$ followed by $\mathrm{B}, \mathrm{A}$ and $\mathrm{AB}$ in patients with rheumatic disease and healthy donors. Individuals with blood group A had lower risk of developing rheumatic diseases compared to other blood types.
\end{abstract}

Keywords: ABO Blood-group System, Blood Donors, Blood Groups, Rheumatic Diseases

\section{Introduction}

Rheumatic diseases are a group of autoimmune disorders of musculoskeletal system and connective tissue affecting a wide range of age groups and causes disability in terms of poor quality of life, loss of productivity ultimately leading to significant health and socioeconomic burden $[1,2]$. Pathogenesis of rheumatic diseases is multifactorial, involving various genetic and environmental risk factors [3, 4]. Both ABO and Rhesus (Rh) blood group systems have been important genetic factors associated with rheumatic diseases $[5,6]$.

In 1901, Karl Landsteiner discovered the ABO blood type system and classified blood groups as $\mathrm{A}, \mathrm{B}, \mathrm{AB}$ or $\mathrm{O}$ based on the presence or absence of $\mathrm{A}$ and $\mathrm{B}$ antigens on the surface of red blood cells (RBCs) [7, 8]. According to the Rh system, blood groups can also be classified as either Rh (-) or $\mathrm{Rh}(+)$ depending on the presence of $\mathrm{Rh} \mathrm{D}$ antigen on the surface of RBCs [9]. The ABO antigens are complex carbohydrates that are additionally expressed on the epithelium, neurons, platelets, and vascular endothelial cells $[7,10]$. Beside their variable structural diversity, they are involved in immune mechanisms that render susceptibility or protection against diseases [11]. Association between blood group A and risk of stomach cancer was first reported in 1953 , and that of $\mathrm{ABO}$ and $\mathrm{Rh}$ blood groups with cancer [12, $13]$, hypercoagulability [14], infections $[15,16]$, and diabetes mellitus [17] have been demonstrated subsequently.

The interactions between the products of $\mathrm{ABO}$ gene and 
proinflammatory cytokines like tumor necrosis factor $\alpha$ and intercellular adhesion molecule 1 (ICAM-1) have been implicated in systemic inflammatory response [18, 19]. These proinflammatory cytokines play a critical role in pathogenesis of rheumatic diseases [20-22]. Therefore, ABO antigen system may be involved in key immune mechanisms that are involved in pathogenesis and progression of rheumatic diseases. Recently, a case-control study suggested an association between $\mathrm{AB}$ blood group and the occurrence and severity of primary knee osteoarthritis (OA) [18]. However, only few studies evaluated the relationship between rheumatic diseases and blood types $[5,6]$. The comparison of distribution of blood types in Indian patients with and without rheumatic disease has not been published so far. In this study, we compared the distribution of $\mathrm{ABO}$ and $\mathrm{Rh}$ blood types between patients with rheumatic diseases, and that of healthy blood donors. The study also assessed the association between types of rheumatic diseases and $\mathrm{ABO}$ and $\mathrm{Rh}$ blood groups.

\section{Methods}

\subsection{Study Design and Methodology}

This was a retrospective observational study conducted at the Department of Rheumatology, Yashoda Hospital, Secunderabad, Telangana, India. The anonymized medical records of patients with rheumatic diseases who attended hospital from September 2015 to January 2020 and the documented evidence of blood group of healthy blood donors were collected. Rheumatic diseases studied were adult-onset Still's disease (AOSD), chikunguniya arthritis, enteropathic arthritis (EA), fibromyalgia, gout, idiopathic inflammatory myopathies (IIM), granulomatosis with polyangiitis (GPA), mixed connective tissue disease (MCTD), OA, primary antiphospholipid syndrome (APS), primary Sjogren's syndrome (primary SS), psoriatic arthritis (PsA), rheumatoid arthritis (RA), rhupus, sarcoidosis, systemic lupus erythematosus (SLE), spondyloarthritis (SpA), systemic sclerosis (SSc), vasculitis and inflammatory arthritis: undifferentiated (UD).

\subsection{Data Collection and Study Outcomes}

Data regarding age, gender $\mathrm{ABO}$ and $\mathrm{Rh}$ blood types and the type of rheumatic disease were collected from medical records. The main study outcome was the distribution of $\mathrm{ABO}$ and $\mathrm{Rh}$ blood groups in patients with rheumatic disease and healthy donors. Association between rheumatic diseases and the $\mathrm{ABO}$ and $\mathrm{Rh}$ blood groups, and gender was determined statistically.

\subsection{Ethics}

The study was approved by the Institutional Ethics Committee and was conducted in accordance with the principles of the Declaration of Helsinki. As this was a retrospective study, a waiver for obtaining informed consent from patients with rheumatic disease was granted. Individuals with good health, mental alertness and physical fitness were selected as healthy blood donors, and were required to complete a registration form. The signed questionnaire document and informed consent were then obtained from them.

\subsection{Statistical Analysis}

The statistical evaluation of data was performed using SAS $^{\circledR}$ version 9.4, SAS Institute Inc., Cary, North Carolina, USA. The data are presented as numbers and percentages. A chi-square test was used to evaluate categorical data, and logistic regression analysis was performed to assess the relationship between gender, $\mathrm{ABO}$ and $\mathrm{Rh}$ blood groups and rheumatic diseases. The statistical analysis was performed at 95\% confidence interval and $P<0.05$ was considered statistically significant.

\section{Results}

Overall, data of 8165 individuals (healthy donors $[n=5000]$ and patients with rheumatic disease $[n=3165])$ were included in this study (Table 1). The mean age of patients with rheumatic diseases was $45.56 \pm 13.08$ years and that of healthy individuals was $30.20 \pm 7.78$ years $(P<0.0001)$. Gender distribution was not homogeneous between the groups with a remarkably higher percentage of men in the group of healthy individuals than in the group of patients with rheumatic diseases (98.64\% [n=4932] vs. $28.25 \%$ [n=894], $P<0.0001)$.

Table 1. Distribution of $A B O$ and Rh blood groups in patients with $R D$ and healthy individuals

\begin{tabular}{|c|c|c|c|c|}
\hline & Patients with RD, $n=3165$ & Healthy individuals, $n=5000$ & Total, $\mathbf{N}=8165$ & Significance \\
\hline Age, years & $45.56 \pm 13.08$ & $30.20 \pm 7.78$ & - & $\begin{array}{l}P<0.0001^{*} \\
\chi^{2}=4698.56\end{array}$ \\
\hline Men & $894(28.25)$ & $4932(98.64)$ & $5828(70.84)$ & $\begin{array}{l}\mathrm{df}=1 \\
P<0.0001\end{array}$ \\
\hline Blood group & & & & \multirow{5}{*}{$\begin{array}{l}\chi^{2}=22.94 \\
\mathrm{df}=3 \\
P<0.0001\end{array}$} \\
\hline A & $559(17.66)$ & $1074(21.48)$ & $1633(20.00)$ & \\
\hline B & $1051(33.21)$ & $1504(30.08)$ & $2555(31.29)$ & \\
\hline $\mathrm{O}$ & $1359(42.94)$ & $2157(43.14)$ & $3516(43.06)$ & \\
\hline $\mathrm{AB}$ & $196(6.19)$ & $265(5.30)$ & $461(5.65)$ & \\
\hline $\mathrm{Rh}(+)$ & $295(93.49)$ & $4714(94.28)$ & $7673(93.97)$ & \multirow{2}{*}{$\begin{array}{l}\chi^{2}=2.13 \\
\mathrm{df}=1 \\
P=0.1445\end{array}$} \\
\hline $\operatorname{Rh}(-)$ & $206(6.51)$ & $286(5.72)$ & $492(6.03)$ & \\
\hline
\end{tabular}

Data are presented as n $(\%)$ or mean $\pm \mathrm{SD}, *$ using t-test. Rh- Rhesus, RD- Rheumatic diseases 
Distribution of $\mathrm{ABO}$ and $\mathrm{Rh}$ blood types in both groups is presented in Table 1. In total, 3516 (43.06\%) patients had blood group O; $2555(31.29 \%), \mathrm{B} ; 1633(20.00 \%), \mathrm{A}$; and 461 (5.65\%), AB. When compared between the groups, blood type A was more common in healthy donors compared to patients with rheumatic diseases $\left(21.48 \%\right.$ vs. $17.66 \%, \quad \chi^{2}=22.94$;
$P<0.0001)$. According to $\mathrm{Rh}$ classification, overall 7673 (93.97\%) patients were $\mathrm{Rh}(+)$ and 492 (6.03\%) patients were $\mathrm{Rh}(-)$. The $\mathrm{Rh}(+)$ blood group was more prevalent compared to $\mathrm{Rh}(-)$ in healthy donors and in patients with rheumatic diseases, and no difference was observed in the Rh distribution between the groups $\left(\chi^{2}=2.13 ; P=0.1445\right)$ (Table 1$)$.

Table 2. Distribution of $A B O$ blood groups in patients with $R D$

\begin{tabular}{|c|c|c|c|c|c|c|}
\hline \multirow{2}{*}{ Type of RD } & \multicolumn{4}{|c|}{ Distribution of patients according to $\mathrm{ABO}$ blood groups, $\mathrm{n}(\%)$} & \multirow{2}{*}{ Total } & \multirow{2}{*}{ Type of RD } \\
\hline & A & $\mathbf{A B}$ & B & $\mathbf{O}$ & & \\
\hline AOSD & $0(0.00)$ & $0(0.00)$ & $1(100.00)$ & $0(0.00)$ & $1(100)$ & \\
\hline Chikungunya arthritis & $2(40.00)$ & $0(0.00)$ & $2(40.00)$ & $1(20.00)$ & $5(100)$ & \\
\hline EA & $2(66.67)$ & $0(0.00)$ & $1(33.33)$ & $0(0.00)$ & $3(100)$ & \\
\hline Fibromyalgia & $0(0.00)$ & $0(0.00)$ & $0(0.00)$ & $1(100.00)$ & $1(100)$ & \\
\hline Gout & $25(21.37)$ & $5(4.27)$ & $32(27.35)$ & $55(47.01)$ & $117(100)$ & \\
\hline GPA & $1(33.33)$ & $0(0.00)$ & $0(0.00)$ & $2(66.67)$ & $3(100)$ & \\
\hline Inflammatory arthritis: UD & $1(25.00)$ & $0(0.00)$ & $3(75.00)$ & $0(0.00)$ & $4(100)$ & \\
\hline IIM & $1(14.29)$ & $1(14.29)$ & $0(0.00)$ & $5(71.43)$ & $7(100)$ & \\
\hline MCTD & $5(10.87)$ & $4(8.70)$ & $17(36.96)$ & $20(43.48)$ & $46(100)$ & $\chi^{2}=62.34$ \\
\hline OA & $49(15.56)$ & $19(6.03)$ & $101(32.06)$ & $146(46.35)$ & $315(100)$ & $\mathrm{df}=57$ \\
\hline APS & $0(0.00)$ & $0(0.00)$ & $3(60.00)$ & $2(40.00)$ & $5(100)$ & $P=0.2921$ \\
\hline Primary SS & $18(24.00)$ & $4(5.33)$ & $28(37.33)$ & $25(33.33)$ & $75(100)$ & \\
\hline PsA & $20(18.35)$ & $12(11.01)$ & $39(35.78)$ & $38(34.86)$ & $109(100)$ & \\
\hline RA & $246(16.18)$ & $89(5.86)$ & $526(34.61)$ & $659(43.36)$ & $1520(100)$ & \\
\hline Rhupus & $4(21.05)$ & $2(10.53)$ & $3(15.79)$ & $10(52.63)$ & $19(100)$ & \\
\hline Sarcoidosis & $0(0.00)$ & $0(0.00)$ & $1(25.00)$ & $3(75.00)$ & $4(100)$ & \\
\hline SLE & $39(17.11)$ & $11(4.82)$ & $82(35.96)$ & $96(42.11)$ & $228(100)$ & \\
\hline $\mathrm{SpA}$ & $138(20.72)$ & $45(6.76)$ & $200(30.03)$ & 283 (42.49) & $666(100)$ & \\
\hline $\mathrm{SSc}$ & $7(25.00)$ & $4(14.29)$ & $9(32.14)$ & $8(28.57)$ & $28(100)$ & \\
\hline Vasculitis & 1 (11.11) & $0(0.00)$ & $3(33.33)$ & $5(55.56)$ & $9(100)$ & \\
\hline
\end{tabular}

AOS- Adult-onset Still's disease, EA- Enteropathic arthritis, GPA- Granulomatosis with polyangiitis, IIM- Idiopathic inflammatory myopathies, MCTDMixed connective tissue disease, OA- Osteoarthritis, APS- Primary antiphospholipid syndrome, SS- Sjogren's syndrome, PsA- Psoriatic arthritis, SLESystemic lupus erythematosus, RD- Rheumatic disease, RA- Rheumatoid arthritis, SpA- Spondyloarthritis, SSc- Systemic sclerosis, UD- Undifferentiated

Table 3. Distribution of Rh blood type in patients with $R D$

\begin{tabular}{|c|c|c|c|c|}
\hline \multirow{2}{*}{ Type of RD } & \multicolumn{2}{|c|}{ Distribution of patients according to Rh blood types, $\mathrm{n}(\%)$} & \multirow{2}{*}{ Total, N (\%) } & \multirow{2}{*}{ Significance } \\
\hline & Rh $(+)$ & $\mathbf{R h}(-)$ & & \\
\hline AOSD & $1(100.00)$ & $0(0.00)$ & $1(100)$ & \multirow{20}{*}{$\begin{array}{l}\chi^{2}=6.299 \\
\mathrm{df}=19 \\
P=0.9971\end{array}$} \\
\hline Chikungunya arthritis & $5(100.00)$ & $0(0.00)$ & $5(100)$ & \\
\hline EA & $3(100.00)$ & $0(0.00)$ & $3(100)$ & \\
\hline Fibromyalgia & $1(100.00)$ & $0(0.00)$ & $1(100)$ & \\
\hline Gout & $111(94.87)$ & $6(5.13)$ & $117(100)$ & \\
\hline GPA & $3(100.00)$ & $0(0.00)$ & $3(100)$ & \\
\hline Inflammatory arthritis: UD & $4(100.00)$ & $0(0.00)$ & $4(100)$ & \\
\hline IIM & $7(100.00)$ & $0(0.00)$ & $7(100)$ & \\
\hline MCTD & $42(91.30)$ & $4(8.70)$ & $46(100)$ & \\
\hline $\mathrm{OA}$ & $296(93.97)$ & $19(6.03)$ & $315(100)$ & \\
\hline APS & $5(100.00)$ & $0(0.00)$ & $5(100)$ & \\
\hline Primary SS & $68(90.67)$ & $7(9.33)$ & $75(100)$ & \\
\hline PsA & $101(92.66)$ & $8(7.34)$ & $109(100)$ & \\
\hline RA & $1420(93.42)$ & $100(6.58)$ & $1520(100)$ & \\
\hline Rhupus & $19(100.00)$ & $0(0.00)$ & $19(100)$ & \\
\hline Sarcoidosis & $4(100.00)$ & $0(0.00)$ & $4(100)$ & \\
\hline SLE & $213(93.42)$ & $15(6.58)$ & $228(100)$ & \\
\hline $\mathrm{SpA}$ & $621(93.24)$ & $45(6.76)$ & $666(100)$ & \\
\hline $\mathrm{SSc}$ & $26(92.86)$ & $2(7.14)$ & $28(100)$ & \\
\hline Vasculitis & $9(100.00)$ & $0(0.00)$ & $9(100)$ & \\
\hline
\end{tabular}

AOSD- Adult-onset Still's disease, EA- Enteropathic arthritis, GPA- Granulomatosis with polyangiitis, IIM- Idiopathic inflammatory myopathies, MCTDMixed connective tissue disease, OA- Osteoarthritis, APS- Primary antiphospholipid syndrome, SS- Sjogren's syndrome, PsA- Psoriatic arthritis, SLESystemic lupus erythematosus, RD- Rheumatic disease, RA- Rheumatoid arthritis, SpA- Spondyloarthritis, SSc- Systemic sclerosis, UD- Undifferentiated

Although no specific pattern was observed in the distribution of ABO blood groups $\left(\chi^{2}=62.34, P=0.2921\right)$ in patients with different types of rheumatic diseases, blood type $\mathrm{O}$ was more common in patients with fibromyalgia, gout, GPA, IIM, MCTD, 
OA, RA, rhupus, sarcoidosis, SLE, SpA, and vasculitis (Table 2). In addition, results show that blood group $B$ was commonly observed in patients with AOSD, inflammatory arthritis: UD, APS, primary SS, PsA and SSc. In patients with chikunguniya arthritis, blood types A and B were equally distributed, while blood group A was more common in patients with EA. Blood group $\mathrm{AB}$ was least commonly observed in patients with different types of rheumatic diseases.

The $\mathrm{Rh}$ distribution in patients with different types of rheumatic diseases is summarized in Table 3. Rh (+) was more prevalent in all types of rheumatic diseases with overall distribution of $\mathrm{Rh}$ groups being similar among patients with different types of rheumatic diseases $\left(\chi^{2}=6.299, P=0.9971\right)$.

Overall, females had higher risk of rheumatic diseases compared to males (OR [95\% CI]: 184.46 [143.41 - 237.25]; $P<0.0001$ ) (Table 4). Due to a negative association (correlation coefficient: -0.1535) of blood group A with rheumatic diseases, those patients were at a 6 times lower risk for developing rheumatic diseases compared to blood group $\mathrm{O}$ (0.94 [0.78 - 1.14]; $P<0.0318$ ) (Table 4). When Rh blood type and $\mathrm{ABO}$ grouping were integrated, patients with $\mathrm{A}+$ blood group (0.975 [0.618 - 1.538]; $P=0.0037)$, followed by $\mathrm{O}+$ (1.076 [0.693 - 1.68]; $P=0.0215$ ), had lesser risk for rheumatic diseases compared to those with O- group (Table 4). Considering non-homogeneous distribution of gender between patients of both groups, logistic regression for gender-matched cohort was applied and the results showed that patients with blood group A were significantly less likely to be associated with rheumatic diseases (correlation coefficient: -0.2087 ) compared to those with blood group O (Table 5). Reportedly, other blood types were not predisposing factors that could be associated with the risk for rheumatic diseases.

Table 4. Summary of results for relationship between blood types and RD obtained from logistic regression

\begin{tabular}{|c|c|c|c|c|c|c|}
\hline \multicolumn{7}{|c|}{ Likelihood estimates for relationship of blood type and Rh type with RD } \\
\hline & & Estimate & SE & Wald chi-square & OR (95\% CI) & $P$-value \\
\hline Intercept & & 1.03 & 0.09 & 119.48 & - & $<0.0001$ \\
\hline Gender & Female vs. male & 2.61 & 0.06 & 1650.67 & $184.46(143.41-237.25)$ & $<0.0001^{*}$ \\
\hline \multirow[t]{3}{*}{$\mathrm{ABO}$} & A vs. O & -0.15 & 0.07 & 4.61 & $0.94(0.78-1.14)$ & $0.0318^{*}$ \\
\hline & B vs. O & 0.05 & 0.06 & 0.67 & $1.16(0.99-1.36)$ & 0.4141 \\
\hline & $\mathrm{AB}$ vs. $\mathrm{O}$ & 0.20 & 0.11 & 3.36 & $1.34(1.00-1.79)$ & 0.0667 \\
\hline $\mathrm{Rh}$ & $\mathrm{Rh}(+)$ vs. Rh (-) & -0.10 & 0.07 & 1.99 & $0.82(0.62-1.08)$ & 0.1582 \\
\hline
\end{tabular}

\begin{tabular}{|c|c|c|c|c|c|c|}
\hline \multicolumn{7}{|c|}{ Likelihood estimates for relationship of blood types (combined +/-) with RD } \\
\hline & & Estimate & SE & Wald chi-square & OR $(95 \% \mathrm{CI})$ & $P$ - value \\
\hline Intercept & & 1.10 & 0.11 & 102.50 & - & $<0.0001$ \\
\hline Gender & Female vs. male & 2.61 & 0.06 & 1651.32 & $185.10(143.90-238.11)$ & $<0.0001^{*}$ \\
\hline \multirow[t]{7}{*}{$\mathrm{ABO}$} & $\mathrm{A}+\mathrm{vs} . \mathrm{O}-$ & -0.34 & 0.12 & 8.44 & $0.98(0.62-1.54)$ & $0.0037 *$ \\
\hline & A- vs. O- & 0.21 & 0.28 & 0.57 & $1.69(0.82-3.51)$ & 0.4510 \\
\hline & $\mathrm{B}+\mathrm{vs} . \mathrm{O}-$ & -0.12 & 0.11 & 1.20 & $1.22(0.78-1.90)$ & 0.2725 \\
\hline & B- vs. O- & 0.16 & 0.22 & 0.51 & $1.61(0.86-2.99)$ & 0.4769 \\
\hline & $\mathrm{AB}+$ vs. $\mathrm{O}-$ & 0.01 & 0.16 & 0.004 & $1.39(0.83-2.31)$ & 0.9479 \\
\hline & AB- vs. O- & 0.64 & 0.51 & 1.61 & $2.61(0.78-8.68)$ & 0.2050 \\
\hline & O+ vs. O- & -0.24 & 0.10 & 5.29 & $1.08(0.69-1.68)$ & $0.0215^{*}$ \\
\hline
\end{tabular}

*significant, + positive, - negative, RD- Rheumatic disease, Rh- Rhesus

Table 5. Summary of logistic regression models showing relationship between gender, ABO and Rh blood type and RD

\begin{tabular}{|c|c|c|c|c|c|}
\hline Logistic regression $n$ & & Model 1 & Model 2 & Model 3 & Model 4 \\
\hline \multirow{3}{*}{$\begin{array}{l}\text { Independent variable } \\
\text { coefficient }\end{array}$} & Gender (F) & 2.6087 & - & 2.6086 & 2.6082 \\
\hline & $\mathrm{ABO}(\mathrm{A})$ & -0.1537 & -0.2087 & - & -0.1544 \\
\hline & $\mathrm{Rh}(+)$ & -0.0993 & -0.0680 & -0.0987 & - \\
\hline \multirow{3}{*}{ Model statistics } & Cox \& Snell & 0.4777 & 0.0031 & 0.4772 & 0.4776 \\
\hline & Nagelkerke & 0.6482 & 0.0042 & 0.6475 & 0.6481 \\
\hline & $P$ - value & $<0.0001$ & $<0.0001$ & $<0.0001$ & $<0.0001$ \\
\hline
\end{tabular}

Model 1- combined effect of gender, ABO and Rh blood group, Model 2- Relationship in gender-matched cohort, Model 3- Relationship in ABO-matched cohort, Model 4- Relationship in Rh blood type matched cohort, Rh- Rhesus, RD- Rheumatic diseases

\section{Discussion}

In this retrospective observational study, we assessed the distribution of $\mathrm{ABO}$ and $\mathrm{Rh}$ blood groups in Indian patients with rheumatic diseases and healthy individuals. The most common blood type observed in all the rheumatic diseases was $\mathrm{O}$ followed by $\mathrm{B}, \mathrm{A}$ and $\mathrm{AB}$. On comparing blood groups of patients with rheumatic diseases and healthy blood donors, the blood group A was significantly different between the groups. For Rh blood types, prevalence of $\mathrm{Rh}(+)$ was more common and the distribution of $\mathrm{Rh}(+)$ and $\mathrm{Rh}(-)$ was similar in patients with rheumatic diseases and healthy donors.

Association between the ABO blood group system and various diseases has been reported in several studies [12-18]. To our knowledge, three studies have reported an association between $\mathrm{ABO}$ types and rheumatic disease until date $[5,6,23]$. Stoia et al. was the first to study the relationship between $\mathrm{ABO}$ 
system in rheumatic diseases, and reported blood group A to be the most common followed by $\mathrm{O}, \mathrm{B}$ and $\mathrm{AB}$ [23]. Two other studies in 2017 and 2019 reported similar patterns of ABO distribution, where the most prominent was type $\mathrm{A}$, followed by $\mathrm{O}, \mathrm{B}$ and $\mathrm{AB}[5,6]$. Results of our study are different as the most common blood group observed in the cohort of Indian patients of our study was $\mathrm{O}$ followed by B, A and AB. Further, correlation analysis showed that prevalence of rheumatic diseases was lesser in patients with blood group A, and even after integrating $\mathrm{ABO}$ type with $\mathrm{Rh}+/$ - type in logistic regression, patients with $\mathrm{A}+$ blood group showed lower risk for rheumatic diseases. Distribution of blood groups is known to vary geographically indicating an influence of race and ethnicity. Moreover, in a given population, blood group distribution may vary based on environmental factors, prevalence of various diseases, immigration and exogamous marriages within different ethnic groups [24]. Therefore, different nationalities and races could be the reason behind contradicting observations obtained in this Indian study.

Based on the existing scientific literature, overall distribution of $\mathrm{ABO}$ groups in India shows that $\mathrm{B}$ is the common blood group in northern and western India whereas in the eastern, southern and central parts, $\mathrm{O}$ was reportedly the most prevalent blood group [25]. A multi-centric study by Agrawal et al. reported O blood group to be the most common (37.12\%), which was closely followed by B $(32.26 \%)$, A (22.88\%), and $\mathrm{AB}(7.74 \%)$; and among them $94.61 \%$ were $\mathrm{Rh}$ $(+)$ in the Indian healthy blood donors [26]. Our findings are similar to those reported by Agrawal et al. [26] as blood group $\mathrm{O}$ was predominant followed by $\mathrm{B}, \mathrm{A}$ and $\mathrm{AB}$ groups; and $\mathrm{Rh}$ $(+)$ blood type was predominant in healthy blood donors. Cumulatively, $\mathrm{O}$ was the dominant blood group in the Indian population $[25,26]$. Distribution of blood groups followed similar trend in healthy blood donors and patients with rheumatic disease in our study. In line with the previous studies $[5,6,23,27]$, our data shows that $\mathrm{AB}$ was the least common blood type in patients with rheumatic diseases. Recently, it was reported that $\mathrm{A}$ and $\mathrm{Rh}(+)$ blood types were found to be more prevalent among patients with RA, SpA, connective tissue disorders and vasculitis; whereas $\mathrm{O}$ and $\mathrm{Rh}$ $(+)$ blood types were more common in those with SLE, SSc and SS [6]. However, in our study for RA, SpA and SLE, blood type $\mathrm{O}$, and in primary $\mathrm{SS}$ and SSc, blood type B was more prevalent in patients. Other studies reported higher prevalence rate of blood type $\mathrm{O}$ in patients with $\mathrm{SpA}$ [27], and A in those with discoid lupus erythematosus [28]. Additionally, in contrast to the association of blood type $\mathrm{AB}$ with primary OA published previously in a case-control study, our study shows blood group $\mathrm{O}$ to be more prevalent in patients with $\mathrm{OA}$ [18]. Further, blood types A and B were equally prevalent in patients with chikunguniya arthritis in our study, which contrasted to the association between types $\mathrm{AB}$ and A reported previously by Kumar et al. [15] There are no existing studies until date that show association of $\mathrm{ABO}$ and $\mathrm{Rh}$ blood groups for AOSD, EA, fibromyalgia, gout, GPA, inflammatory arthritis: UD, APS, PsA, rhupus and sarcoidosis. Whereas, our study reported that blood type $\mathrm{O}$ was more common in patients with fibromyalgia, gout, GPA, rhupus and sarcoidosis; type B was commonly seen in those with AOSD, inflammatory arthritis: UD, APS and PsA; and type A, in patients with EA.

Overall, this study reports similar as well as divergent results compared to previously published studies. This could be due to different factors such as genetics, diet, environment, lifestyle, etc. that might have influenced the onset of diseases with complex genetic etiologies. Blood groups have been previously shown as hematological markers, and the relationship of $\mathrm{ABO}$ and $\mathrm{Rh}$ blood types with various diseases have been documented; however, the underlying mechanisms involved in the pathogenesis of diseases, remains unclear [7, $12,14]$. Various proinflammatory cytokines, adhesion molecules, and genetic predisposition (human leukocyte antigen (HLA) genes) have been implicated in the pathogenesis of rheumatic diseases [5, 20-22, 29]. Similarly, any possible relationship of these factors and $\mathrm{ABO}$ antigens could explain the diverse distribution of $\mathrm{ABO}$ blood type in rheumatic diseases $[2,6,18,19]$.

To the best of our knowledge, the present study is a first-of-its-kind addressing an association between rheumatic diseases and blood types in the Indian cohort. Strength of our study could be attributed to the large population size of both healthy donors and patients with rheumatic diseases. However, this study was conducted at a single center that reported data from Southern India. Hence, the results may not be representative of the other regions of the country or be corroborated as real-world data. Additionally, no genetic analysis was carried out as it was beyond the scope of the study. In addition, the gender distribution was not homogeneous between the groups. Hence, a multi-centric study with genetic analyses could be carried out in the future that could help meet the healthcare challenges related to rheumatic diseases.

\section{Conclusion}

Our study is the first to show a relationship of $\mathrm{ABO}$ and $\mathrm{Rh}$ blood groups with rheumatic diseases in Indian patients. Blood type $\mathrm{O}$ was the most common ABO type and $\mathrm{Rh}(+)$ was the most common $\mathrm{Rh}$ type in healthy donors and in patients with rheumatic diseases. Distribution of ABO groups among rheumatic disease types was similar. Individuals with blood type A are less likely to develop rheumatic diseases compared to other blood types. However, a multi-centric study across India involving a larger patient population is warranted.

\section{Conflict of Interest}

All authors have no conflict of interest to declare.

\section{Authorship}

Conception and design of study - A. N. R; Data acquisition, statistical analysis and interpretation - Y. A. K., R. L. T.; Drafting, revision and final approval of manuscript - A. N. R., Y. A. K., R. L. T. All authors meet the International Committee of Medical Journal Editors (ICMJE) criteria for 
authorship of this manuscript, and take complete responsibility for accuracy of the data analysis and integrity and work as a whole.

\section{Acknowledgements}

Authors thank Dr. N Rama Subramaniam, Consultant Transfusion Medicine, Yashoda Hospital, Secunderabad, Telangana, India for providing data on healthy donors for this study. Authors acknowledge CBCC Global Research for providing statistical analysis and scientific writing assistance for development of this manuscript.

\section{References}

[1] Chopra A. (2015). Disease burden of rheumatic diseases in India: COPCORD perspective. Indian Journal of Rheumatology, 10 (2), 70-77.

[2] Kato M, Yasuda S, Atsumi T. (2018). The role of genetics and epigenetics in rheumatic diseases: are they really a target to be aimed at? Rheumatology International, 38 (8), 1333-1338.

[3] Sparks JA, Costenbader KH. (2014). Genetics, environment, and gene-environment interactions in the development of systemic rheumatic diseases. Rheumatic Diseases Clinics of North America, 40 (4), 637-657.

[4] Van Steenbergen HW, Huizinga TW, van der Helm-van Mil AH. (2013). The preclinical phase of rheumatoid arthritis: what is acknowledged and what needs to be assessed? Arthritis and Rheumatism, 65 (9), 2219-2232.

[5] Karadağ A. (2019). Comparison of distribution of blood groups in inflammatory rheumatic diseases and healthy subjects. Cumhuriyet Medical Journal, 41, 516-523.

[6] Çildağ S, Kara Y, Şentürk T. (2017). ABO blood groups and rheumatic diseases. European Journal of Rheumatology, 4 (4), 250-253.

[7] Franchini M, Liumbruno GM. (2013). ABO blood group: old dogma, new perspectives. Clinical Chemistry and Laboratory Medicine, 51 (8), 1545-1553.

[8] Groot HE, Sierra LEV, Said MA, Lipsic E, Karper JC, van der Harst P. (2020). Genetically determined ABO blood group and its associations with health and disease. Arteriosclerosis, Thrombosis, and Vascular Biology, 40 (3), 830-838.

[9] Mouro I, Colin Y, Chérif-Zahar B, Cartron JP, Le Van Kim C. (1993). Molecular genetic basis of the human Rhesus blood group system. Nature Genetics, 5 (1), 62-65.

[10] Liumbruno GM, Franchini M. (2013). Beyond immunohaematology: the role of the $\mathrm{ABO}$ blood group in human diseases. Blood Transfusion=Trasfusione del sangue, $11(4), 491-499$.

[11] Imberty A, Varrot A. (2008). Microbial recognition of human cell surface glycoconjugates. Current Opinion in Structural Biology, 18 (5), 567-576.

[12] Zhang BL, He N, Huang YB, Song FJ, Chen KX. (2014). $\mathrm{ABO}$ blood groups and risk of cancer: a systematic review and meta-analysis. Asian Pacific Journal of Cancer Prevention: APJCP, 15 (11), 4643-4650.
[13] Aird I, Bentall HH, Roberts JAF. (1953). A relationship between cancer of stomach and the ABO blood groups. British Medical Journal, 1 (4814), 799-801.

[14] Franchini M, Favaloro EJ, Targher G, Lippi G. (2012). ABO blood group, hypercoagulability, and cardiovascular and cancer risk. Critical Reviews in Clinical Laboratory Sciences, 49 (4), 137-149.

[15] Kumar NC, Nadimpalli M, Vardhan VR, Gopal SD. (2010). Association of $\mathrm{ABO}$ blood groups with Chikungunya virus. Virology Journal, 7, 140.

[16] Panda AK, Panda SK, Sahu AN, Tripathy R, Ravindran B, Das BK. (2011) Association of ABO blood group with severe falciparum malaria in adults: case control study and meta-analysis. Malaria Journal, 10, 309.

[17] Meo SA, Rouq FA, Suraya F, Zaidi SZ. (2016) Association of $\mathrm{ABO}$ and $\mathrm{Rh}$ blood groups with type 2 diabetes mellitus. European Review for Medical and Pharmacological Sciences, 20 (2), 237-242.

[18] Li C, Ouyang N, Wang X, Liang A, Mo Y, Li S, Qiu J, Fang G, Fu Y, Song B, Chen Z, Ding Y. (2019). Association between the $\mathrm{ABO}$ blood group and primary knee osteoarthritis: A case-control study. Journal of -Orthopaedic Translation, 21, 129-135.

[19] Paré G, Chasman DI, Kellogg M, Zee RY, Rifai N, Badola S, Miletich JP, Ridker PM. (2008) Novel association of ABO histo-blood group antigen with soluble ICAM-1: results of a genome-wide association study of 6,578 women. PLoS Genetics, 4 (7), e1000118.

[20] Yi YS. (2018). Role of inflammasomes in inflammatory autoimmune rheumatic diseases. The Korean journal of physiology \& pharmacology: official journal of the Korean Physiological Society and the Korean Society of Pharmacology, 22 (1), 1-15.

[21] Hjeltnes G, Hollan I, Førre O, Wiik A, Lyberg T, Mikkelsen K, Agewall S. (2013). Serum levels of lipoprotein (a) and E-selectin are reduced in rheumatoid arthritis patients treated with methotrexate or methotrexate in combination with TNF- $\alpha$-inhibitor. Clinical and Experimental Rheumatology, 31 (3), 415-421.

[22] McMurray RW. (1996). Adhesion molecules in autoimmune disease. Seminars in Arthritis and Rheumatism, 25 (4), 215-233.

[23] Stoia I, Ramneantu R, Poitas M. (1967). Blood groups ABO and $\mathrm{Rh}(\mathrm{D})$ factor in the rheumatic diseases. Annals of the Rheumatic Diseases, 26 (4), 332-333.

[24] Farhud DD, Zarif Yeganeh M. (2013). A brief history of human blood groups. Iranian Journal of Public Health, 42 (1), $1-6$.

[25] Shekhar H, Kaur A, Jadeja P, Parihar PM, Mangukiya KK. (2014). Frequency and distribution of ABO blood group and $\mathrm{Rh}$ (D) factor in southern Rajasthan. International Journal of Science \& Nature, 5 (3), 494-497.

[26] Agrawal A, Tiwari AK, Mehta N, Bhattacharya P, Wankhede R, Tulsiani S, Kamath S. (2014). ABO and Rh (D) group distribution and gene frequency; the first multicentric study in India. Asian Journal of Transfusion Science, 8 (2), 121-125. 
[27] Shinebaum R, Blackwell CC, Forster PJ, Hurst NP, Weir DM, Nuki G. (1987), Non-secretion of ABO blood group antigens as a host susceptibility factor in the spondyloarthropathies. British Medical Journal (Clinical research ed.), 294 (6566), 208-210.

[28] Tamega Ade A, Bezerra LV, Pereira Fde P, Miot HA. (2009) Blood groups and discoid lupus erythematosus. Anais Brasileiros de Dermatologia, 84 (5), 477-481.

[29] Okada Y, Wu D, Trynka G, Raj T, Terao C, Ikari K, Kochi Y, Ohmura K, Suzuki A, Yoshida S, Graham RR, Manoharan A, Ortmann W, Bhangale T, Denny JC, Carroll RJ, Eyler AE, Greenberg JD, Kremer JM, Pappas DA, Jiang L, Yin J, Ye L, Su DF, Yang J, Xie G, Keystone E, Westra HJ, Esko T, Metspalu A, Zhou X, Gupta N, Mirel D, Stahl EA, Diogo D,
Cui J, Liao K, Guo MH, Myouzen K, Kawaguchi T, Coenen MJ, van Riel PL, van de Laar MA, Guchelaar HJ, Huizinga TW, Dieudé P, Mariette X, Bridges SL Jr, Zhernakova A, Toes RE, Tak PP, Miceli-Richard C, Bang SY, Lee HS, Martin J, Gonzalez-Gay MA, Rodriguez-Rodriguez L, Rantapää-Dahlqvist S, Arlestig L, Choi HK, Kamatani Y, Galan P, Lathrop M; RACI consortium; GARNET consortium, Eyre S, Bowes J, Barton A, de Vries N, Moreland LW, Criswell LA, Karlson EW, Taniguchi A, Yamada R, Kubo M, Liu JS, Bae SC, Worthington J, Padyukov L, Klareskog L, Gregersen PK, Raychaudhuri S, Stranger BE, De Jager PL, Franke L, Visscher PM, Brown MA, Yamanaka H, Mimori T, Takahashi A, Xu H, Behrens TW, Siminovitch KA, Momohara S, Matsuda F, Yamamoto K, Plenge RM. (2014) Genetics of rheumatoid arthritis contributes to biology and drug discovery. Nature, 506 (7488), 376-381. 